\title{
Correction to: Risk stratification of pediatric high-grade glioma: a newly proposed prognostic score
}

\author{
Amr Muhammed ${ }^{1}$ (1) $\cdot$ Mohamed S. Gaber ${ }^{1} \cdot$ Mohamed Elbeltagy ${ }^{2} \cdot$ Ahmed El Hemaly $^{3} \cdot$ Hala Taha $^{4} \cdot$ Amal Refaat $^{5}$. \\ Mohamed S. Zaghloul ${ }^{6}$
}

Published online: 18 December 2019

(C) Springer-Verlag GmbH Germany, part of Springer Nature 2019

\section{Correction to: Child's Nervous System (2019) 35:2355-2362 \\ https://doi.org/10.1007/s00381-019-04257-2}

The original version of this article unfortunately contained an error. The author apologizes for having provided an incorrect name: "Mohamed S. Zaghluol" should be "Mohamed S. Zaghloul". Given in this article is the correct author name.

Publisher's note Springer Nature remains neutral with regard to jurisdictional claims in published maps and institutional affiliations.

The online version of the original article can be found at https://doi.org/ 10.1007/s00381-019-04257-2

Amr Muhammed

amr.muhammed@med.sohag.edu.eg

1 Department of Clinical Oncology and Nuclear Medicine, Sohag University Hospital, Sohag, Egypt

2 Department of Neurosurgery Children's Cancer Hospital, Egypt and Faculty of Medicine Cairo University, Cairo, Egypt

3 Department of Pediatric Oncology, National Cancer Institute, Cairo University and Children Cancer Hospital (CCHE), Cairo, Egypt

4 Department of Pathology, National Cancer Institute, Cairo University and Children Cancer Hospital (CCHE), Cairo, Egypt

5 Radio-diagnosis Department, National Cancer Institute \& Children's Cancer Hospital, Cairo, Egypt

6 Department of Radiation Oncology, National Cancer Institute, Cairo University and Children Cancer Hospital (CCHE), Cairo, Egypt 